\title{
Article \\ Comparative Computational Study of L-Amino Acids as Green Corrosion Inhibitors for Mild Steel
}

\author{
Anton Kasprzhitskii ${ }^{1,2, * \mathbb{D}}$, Georgy Lazorenko ${ }^{1,2} \mathbb{D}^{\mathbb{D}}$, Tatiana Nazdracheva ${ }^{3}$ and Victor Yavna ${ }^{1}$ \\ 1 Department of Physics, Rostov State Transport University, Narodnogo Opolcheniya Sq., \\ 344038 Rostov-on-Don, Russia; glazorenko@yandex.ru (G.L.); vay@rgups.ru (V.Y.) \\ 2 Mineralica Limited Liability Company, Skolkovo Innovation Center, 42 Bolshoy Boulevard, \\ 121205 Moscow, Russia \\ 3 Faculty of Physics, Southern Federal University, 5 Zorge Street, 344090 Rostov-on-Don, Russia; \\ nazdracheva98@mail.ru \\ * Correspondence: akasprzhitsky@yandex.ru; Tel.: +7-928-757-9539
}

Citation: Kasprzhitskii, A.;

Lazorenko, G.; Nazdracheva, T.; Yavna, V. Comparative Computational Study of L-Amino Acids as Green Corrosion Inhibitors for Mild Steel. Computation 2021, 9, 1. https://dx. doi.org/10.3390/computation 9010001

Received: 24 November 2020 Accepted: 22 December 2020 Published: 25 December 2020

Publisher's Note: MDPI stays neutral with regard to jurisdictional claims in published maps and institutional affiliations.

Copyright: () 2020 by the authors. Licensee MDPI, Basel, Switzerland. This article is an open access article distributed under the terms and conditions of the Creative Commons Attribution (CC BY) license (https://creativecommons.org/ licenses/by/4.0/).

\begin{abstract}
This research evaluates the inhibitory effect of L-amino acids (AAs) with different side chain lengths on Fe (100) surfaces implementing Monte Carlo (MC) simulation. A quantitative and qualitative description of the adsorption behavior of AAs on the iron surface has been carried out. Calculations have shown that the absolute values of the adsorption energy of L-amino acids increase with side chain prolongation; they are also determined by the presence of heteroatoms. The maximum absolute value of the adsorption energy AAs on the iron surface in accordance with the side chain classification increases in the following sequence: Glu (acidic) $<$ Gln (polar) $<\operatorname{Trp}$ (nonpolar) < Arg (basic). AAs from nonpolar and basic groups have the best adsorption ability to the iron surface, which indicates their highest inhibitory efficiency according to the results of the MC simulation. The calculation results agree with the experimental data.
\end{abstract}

Keywords: corrosion; amino acids; inhibitors; steel; iron; Monte Carlo simulation

\section{Introduction}

Mild steel is a widely used structural material in various industries due to its good mechanical properties, versatility, and relatively low cost [1]. However, mild steel, like many other industrially utilized metals and alloys, has low corrosion resistance [2]. Thus, the protection of mild steel can be achieved with the help of corrosion inhibitors by methods of chemical surface modification to obtain molecular monolayers formed from silanes [3] or phosphonic acids [4], or by the electrochemical reduction of aryldiazonium salts [5]. The most widely applied method for inhibiting or preventing the corrosion of mild steel is the usage of inhibitors, which, in relatively low concentrations, reduce metal corrosion. Many inhibitors are molecular compounds containing heteroatoms and other specific atomic groups that are susceptible to surface adsorption on a metal $[6,7]$. However, taking into account the toxicity of many widely available compounds, in particular nitrites, chromates, and phosphates $[8,9]$, there is a growing need to reduce their usage and completely replace them with new environmentally friendly inhibitors. L-amino acids, which are non-toxic, biodegradable, completely soluble in an aqueous medium, and relatively cheap, can act as a promising alternative to these compounds. All the mentioned facts point to the high potential perspective of their application as "green" corrosion inhibitors [10,11].

The effectiveness of a particular inhibitor depends on many parameters, such as the composition of the corrosive medium, $\mathrm{pH}$ value, temperature, contact time, chemical nature of the inhibitor, type of surface, etc. [12-14]. Recently, there has been a boost in the number of inquiries where theoretical methods based on quantum mechanical and molecular simulation are applied to determine the nature of the molecular interaction of inhibitors with a metal surface and to assess their effectiveness based on these data. 
These methods allow determining not only the mechanism of inhibitor adsorption on the metal surface (by identifying nucleophilic attack and electrophilic attack atomic centers that exchange electrons with the metal), but also an explanation of how corrosive ions penetrate through inhibitor films formed on the metal [15-19]. This gives the possibility of the computational predictive evaluation of a wide class of compounds to identify molecular structures with evident inhibitory properties.

The findings of experimental investigations of L-amino acids [20,21] indicate that they are promising as corrosion inhibitors for iron and its alloys. They have proved that the inhibition mechanism implemented with the help of L-amino acids is connected with the formation of an adsorbed film on the metal surface [22,23]. Thus, it is reasonable to evaluate the efficiency of the corrosion inhibition of L-amino acids based on the determination of the adsorption energy $[24,25]$. In this case, a comparative assessment of the adsorption energies of L-amino acids allows identifying the most promising compounds that provide the maximum corrosion inhibiting effect $[26,27]$.

The aim of this work is to carry out a systematic comparative theoretical survey of the adsorption behavior of L-amino acids (AAs) on the iron surface to identify promising candidates for the role of effective iron corrosion inhibitors using Monte Carlo simulation.

\section{Computational Details}

\subsection{Models}

AAs structures have been taken from the public repository for chemical structures and their bioactivities by the National Center for Biotechnology Information (NCBI) [28] and are registered in Figure 1. The Fe (100) surface was selected to model the adsorption behavior of amino acids. This simple low-index and energetically homogeneous surface is widely used to research the adsorption of molecular compounds on iron [29,30]. An $8 \times 8 \mathrm{Fe}$ (100) surface consisting of eight atomic layers was created basing on a pre-optimized bulk structure with a lattice constant of $2.82 \AA$ [31]. A vacuum layer of $30 \AA$ was applied in the cells (Figure 2) to exclude the influence of atomic layers associated with the imposed periodic boundary conditions.

\subsection{Monte Carlo Simulation}

The molecular structure of the AAs and the Fe bulk structure were preliminarily optimized in the framework of Density Functional Theory (DFT) adopting the CASTEP software package [32]. The research is carried out using the equipment of the shared research facilities of HPC computing resources at Lomonosov Moscow State University $[33,34]$. The calculation of the exchange-correlation energy was performed in the generalized gradient approximation (GGA) [35] exploiting the potential of Perdew, Burke, and Ernzerhof (PBE) [36]. The cut-off energy of the augmented plane wave basis was chosen to be equal to $400 \mathrm{eV}$. This value was selected as a compromise between accuracy and calculation time. The electron-ion interaction was calculated using the Vanderbilt ultrasoft pseudopotential [37], which has a wide range of applications [38,39] and provides a high speed and accuracy of calculation [40], with the valence electron configurations $\mathrm{Fe} 3 \mathrm{~d}^{6} 4 \mathrm{~s}^{2}$, O $2 s^{2} 2 p^{4}, N 2 s^{2} 2 p^{3}, C 2 s^{2} 2 p^{2}$, and $H 1 s^{1}$. Structure optimization was performed through the Broyden-Fletcher-Goldfarb-Shanno (BFGS) algorithm [41]. For the Fe bulk structure, the equilibrium atomic positions were determined in accordance with the following criteria: energy change per ion $\left(10^{-5} \mathrm{eV}\right)$; maximum force $(0.03 \mathrm{eV} / \AA)$; maximum stress $(0.05 \mathrm{GPa})$; maximum displacement $\left(10^{-3} \AA\right)$. A Monkhorst-Pack mesh of $4 \times 4 \times 4$ k-points was used for the cell [42]. The geometric structure of the AAs was optimized in a $40 \times 40 \times 40 \AA$ cell with periodic boundary conditions and $\Gamma$-point. During optimization, the cell parameters were fixed. The contribution of non-covalent forces, such as hydrogen bonds and van der Waals interactions, is taken into account within the hybrid semi-empirical solution as damped atom-pairwise dispersion corrections of the form $C_{6} R^{-6}$ in the DFT formalism according to the Grimme scheme (DFT-D correction) [43]. 


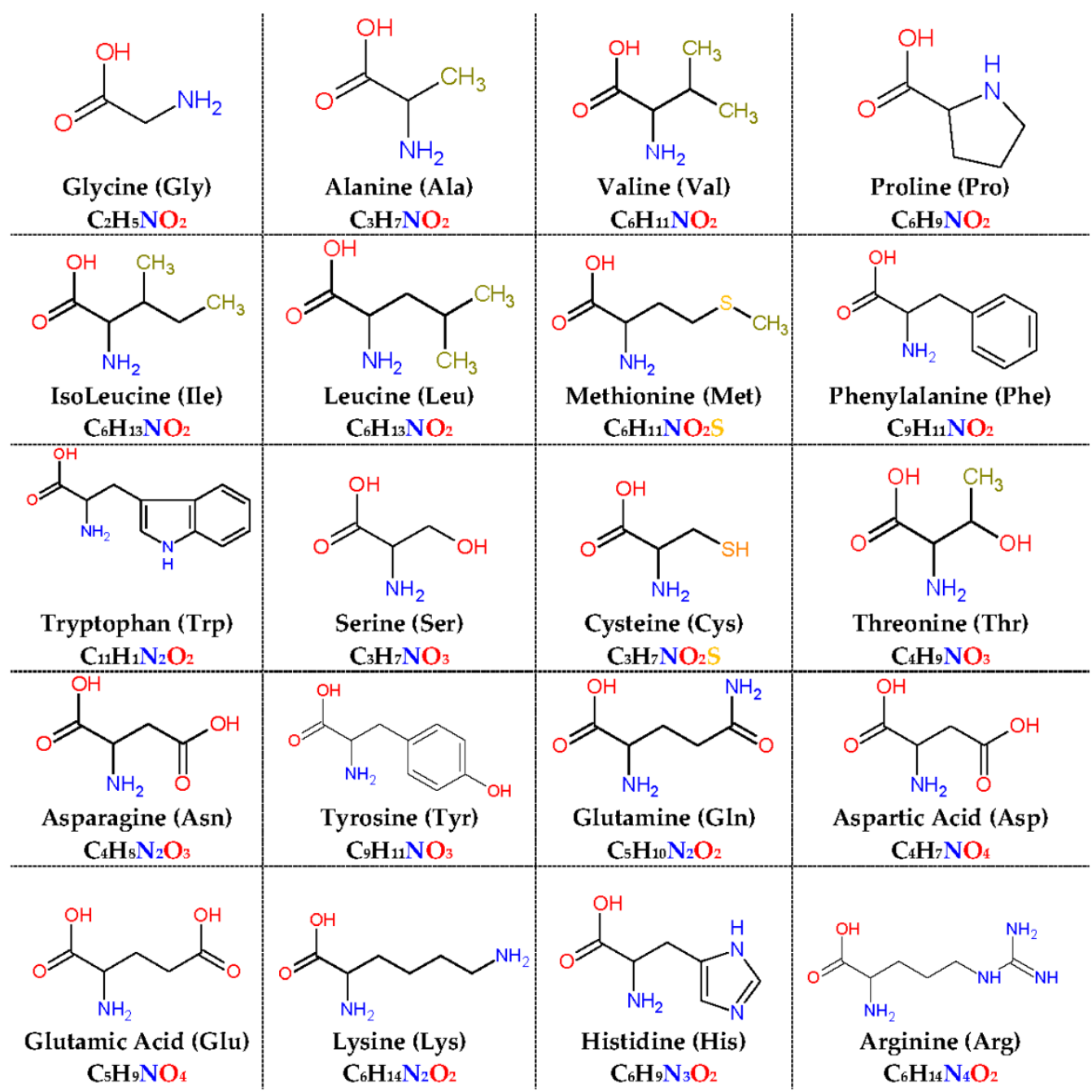

Figure 1. Molecular structure of the investigated L-amino acids.
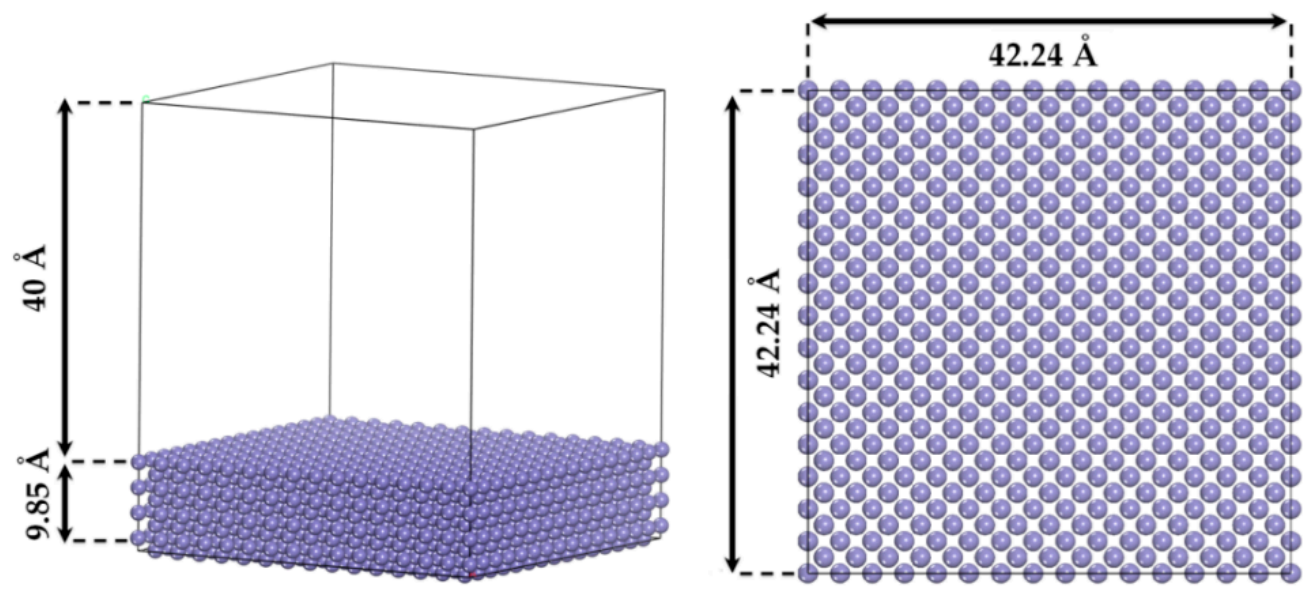

Figure 2. Side-view of the periodic slab for the Fe (100) metal surface used in Monte Carlo simulations.

The adsorption behavior of AAs on the iron surface in the gas phase was investigated by Monte Carlo simulations employing the Adsorption Locator module of the Material Studio software [44]. This approach is used to reveal the characteristic features of the interaction of molecules and metal surfaces without taking into account the influence of the solution [45-49]. The adsorption locator determines the configuration of the adsorbed 
L-amino acid based on the Metropolis algorithm [50]. The search for the global minimum is based on the metaheuristic algorithm simulating annealing with automated temperature control and the following parameters: 10 temperature cycles with 100,000 steps for each [51,52]. For the system L-amino acid/Fe (100) surface, the charges are assigned from DFT calculation by a Mulliken population analysis. The Monte Carlo parameters were set to a probability of 0.32 (ratio $=1)$ for "conformer", "rotate", and "translate", while "regrow" was set to 0.03 (ratio = 0.1). A smart algorithm was used for geometry optimization [44]. The optimization procedure that we have used limits the intramolecular degrees of freedom of the molecule. This is how the relative distances within the molecular groups selected by the algorithm are fixed. In this case, the position of the selected molecular groups and fragments is optimized. This reduces the number of degrees of freedom requiring optimization. Moreover, this allows retaining the configuration of known functional groups during optimization. The COMPASS force field was employed to optimize the structure of L-amino acids in the search for the minimum energy [53]. The choice of the COMPASS force field was made due to the fact that this field rather accurately describes a wide class of organic and inorganic compounds in various phase states [54-56]. It is widely used to research the adsorption behavior of organic molecules on the surface of metals [45-47], including amino acids [27,48,57,58]. It has been displayed in a number of works that the estimation of the affinity of organic molecules with metal surfaces, carried out using the COMPASS force field, is consistent with the experimental data $[47,59,60]$. The optimization of the structure of L-amino acids on the Fe (100) surface was determined in accordance with the following criteria: energy $\left(2 \times 10^{-5} \mathrm{kcal} / \mathrm{mol}\right)$; force $\left(10^{-3} \mathrm{kcal} / \mathrm{mol} . \AA\right)$; displacement $\left(10^{-5} \AA\right)$. No restrictions were imposed on the parameters of the "L-amino acid/Fe (100) surface" system during optimization. The Ewald summation method [61] was applied to describe the electrostatic interaction with an accuracy of $10^{-5} \mathrm{kcal} / \mathrm{mol}$. The Van der Waals interaction energies were calculated implementing the atom-based method with a cubic spline truncation and a cut off distance of $18.5 \AA$.

\section{Results and Discussion}

The investigation of the adsorption behavior of L-amino acids on the Fe (100) surface was carried out by the Monte Carlo (MC) method in the gas phase. The evaluation of the corrosion inhibition efficiency AAs is based on the analysis of the adsorption energy $\left(\mathrm{E}_{a d s}\right)$ of equilibrium low-energy configurations of the structure.

A typical profile of searching for energetically favorable states by the simulating annealing method for the total energy, average total energy, van der Waals energy, electrostatic energy, and intramolecular energy for Thr/Fe (100) surface was obtained by optimizing the entire system (Figure 3). The behavior of the energy characteristics in Figure 3 is typical for the process of optimizing the energy of an organic molecule on a metal surface in the gas phase [59,62]. The transition of the system to an equilibrium state is observed after a series of first cycles of the simulating annealing algorithm to search for the global minimum of the system. The attainment of the minimum for Thr/Fe (100) system is characterized by the appearance of repeating topologies of curves for the energy characteristics of the system after a given number of iterative steps have been performed. Close to constant values of electrostatic and intramolecular energies are observed in the process of searching for the global minimum, which are caused by the limitations of the algorithm imposed on intramolecular interactions between atoms of the L-amino acid [63]. 


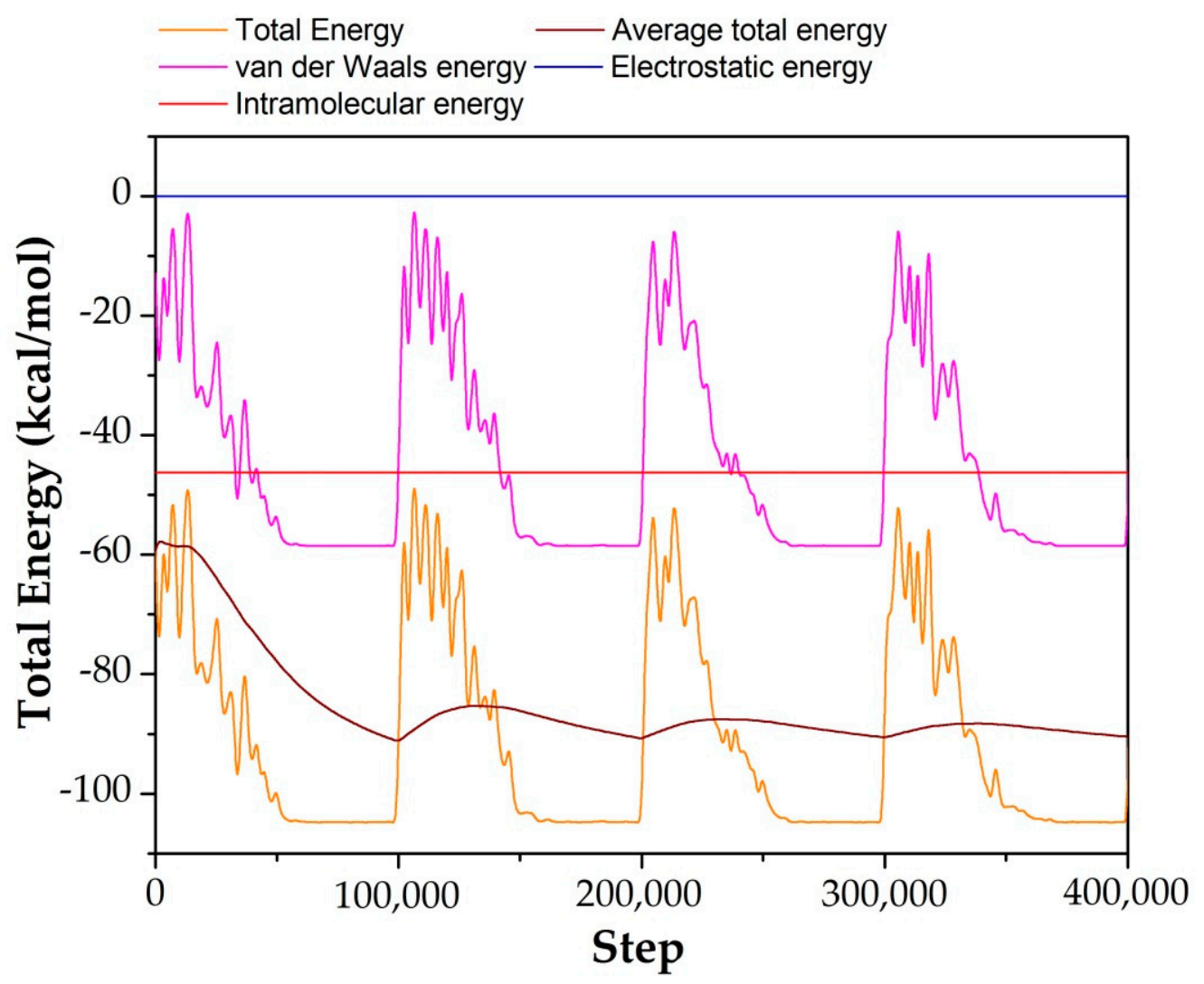

Figure 3. Total energy profile for Thr/Fe (100) system during the energy optimization process.

Figure 4 exhibits the equilibrium low-energy structures of L-amino acids adsorbed on the Fe (100) surface in the gas phase obtained as a result of the MC simulation. It can be seen that all the inhibitor molecules are oriented parallel to the metal surface as a result of adsorption. This indicates an enhanced stability of the formed L-amino acid molecular layer, characterized by the participation of a larger number of L-amino acid atomic centers interacting with the iron surface. In this case, the prolongation of the side chain amino acids will provide an increased affinity for the iron surface. This indicates the ability to protect the iron surface from the effects of an aggressive environment more effectively [64]. In this case, the side chain type will have a key effect on the structure of the adsorption layer, determining the nature of the interaction with the iron surface.

The influence of the side chain type on the equilibrium configuration of L-amino acids during adsorption on the iron surface was determined on the basis of $\mathbf{E}_{a d s}$ using the following formula:

$$
\mathbf{E}_{a d s}=\mathbf{E}_{T}-\left(\mathbf{E}_{A}+\mathbf{E}_{S}\right),
$$

where $\mathbf{E}_{a d s}$ is the energy of the substrate-adsorbate configuration, $\mathbf{E}_{T}$ is the total energy of the system "L-amino acid/Fe (100) surface", and $\mathbf{E}_{A}$ and $\mathbf{E}_{S}$ are the energy of the inhibitor molecule and of the iron surface, respectively. The results of calculating $\mathbf{E}_{a d s}$ are submitted in the diagram in Figure 5. All the values of the adsorption energies are negative, which means that the process can proceed spontaneously. The highest negative adsorption energy indicates the system with the most stable coating. In accordance with the AAs classification by the side chain type, the calculation results manifested in Figure 5 are divided into four groups: nonpolar, polar, acidic, and basic [65]. In each group, one can observe an increment in the absolute value of the adsorption energy of an amino acid on the Fe (100) surface due to a side chain prolongation and the number of heteroatoms. Thus, an increase in the side chain length, which correlates with the values of the adsorption energy of L-amino acids, indicates a multiplication of the number of the adsorption centers for the formation of bonds with the metal surface. 

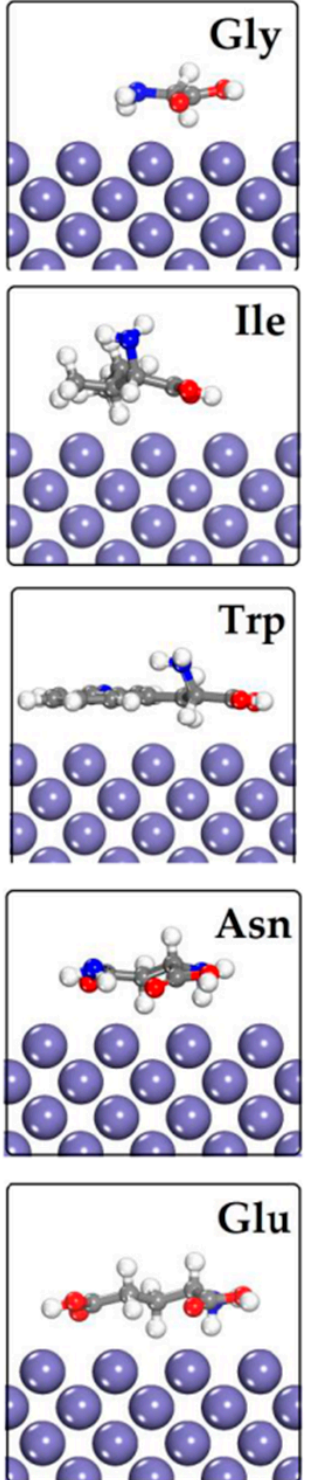
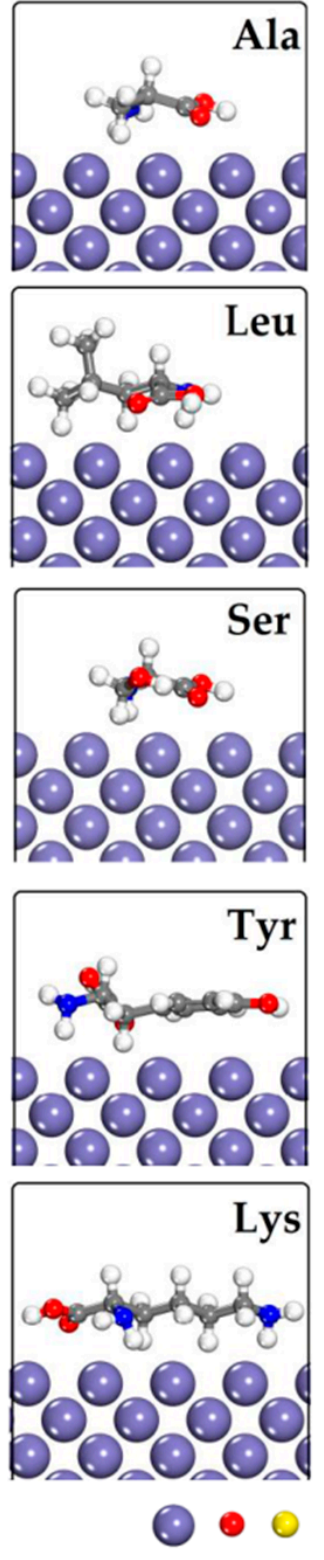

Fe O S
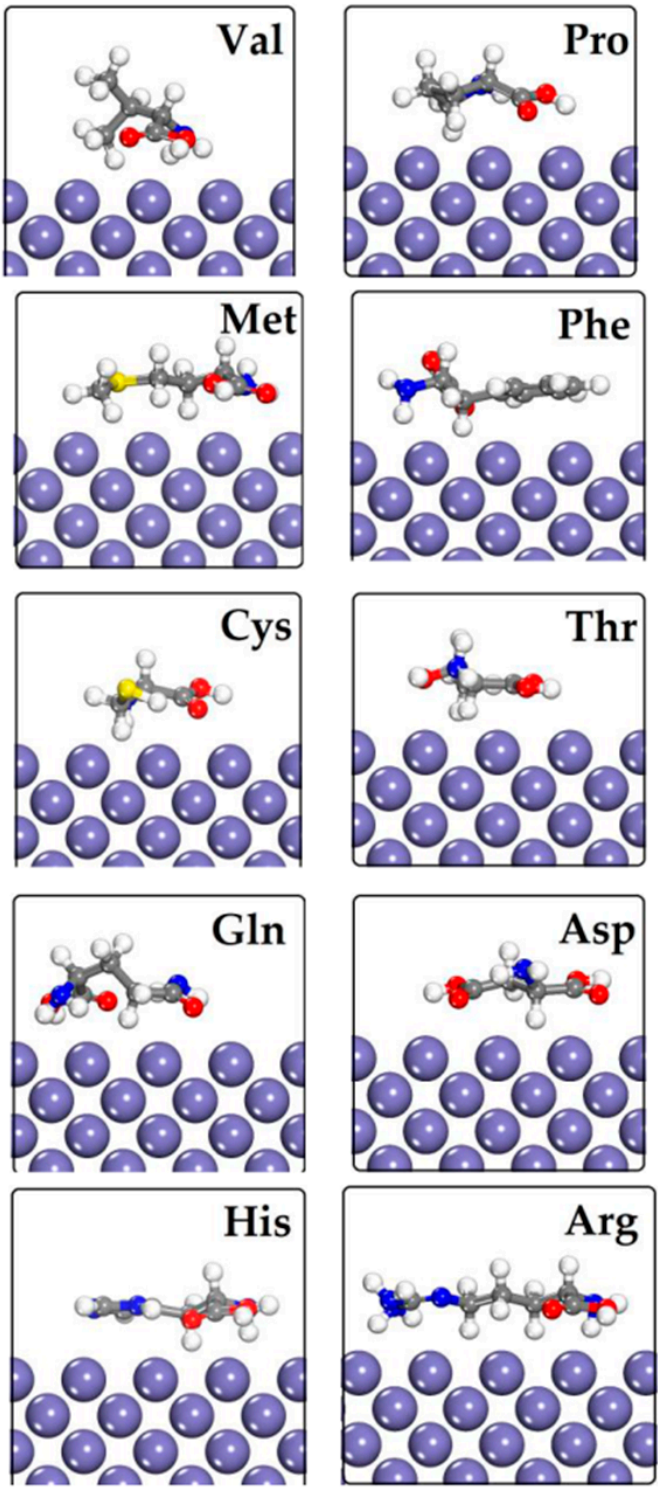

H N C

Figure 4. The side view of the most stable low-energy configurations calculated by the MC simulation for the adsorption of L-amino acids on the Fe (100) surface.

The molecular structure of the side chain affects the nature of the formed bonds of L-amino acid with the metal surface and the affinity for it. The calculation demonstrated (Figure 5) that the maximum absolute value of the adsorption energy of L-amino acids on the Fe (100) surface in accordance with the side chain type classification increases in the following sequence: Glu (acidic) < Gln (polar) < Trp (nonpolar) < Arg (basic). L-amino acids from nonpolar and basic groups have the best adsorption ability to the iron surface, which indicates their highest inhibitory efficiency according to the results of the MC simulation.

At the same time, it should be noted that more accurate estimates can be obtained by taking into account the solution in the model. Another aspect of the influence of the affinity of the inhibitor for the substrate is the size effect due to the influence of the mass of L-amino acids on $\mathbf{E}_{a d s}$. To evaluate this, we performed a calculation of the specific adsorption energy for L-amino acids adsorbed to the iron surface (Figure 6). It can be seen that the adsorption energy per unit mass gives a more uniform distribution of the energy characteristic. At the 
same time, the specific absorption energy for amino acids from the polar group begins to prevail over the non-polar group. This result indicates the possibility of the influence of hydrogen or covalent bonds which can form at L-amino acids in the solution.

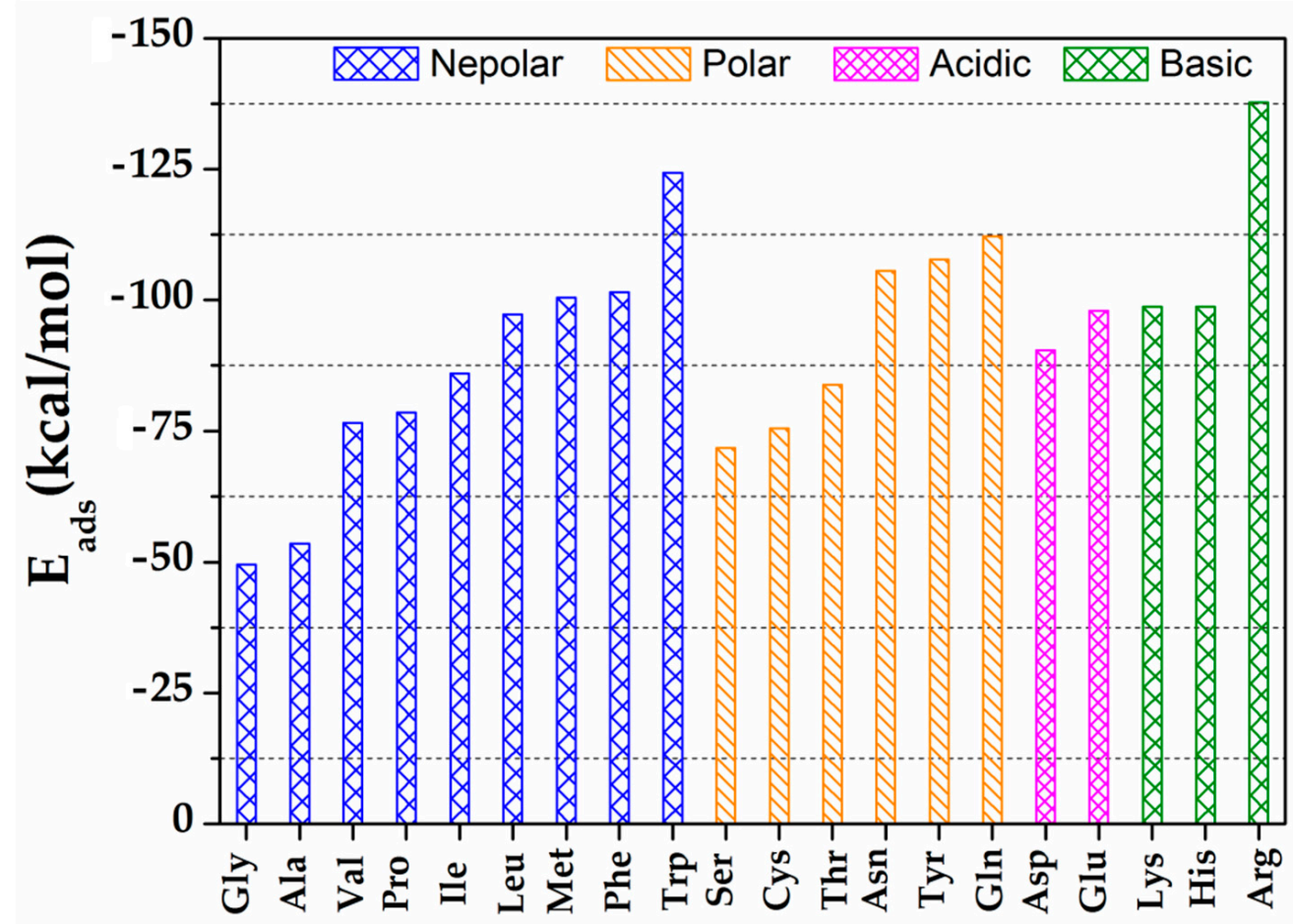

Figure 5. The adsorption energy $\left(\mathrm{E}_{a d s}\right)$ obtained from the Monte Carlo simulations of L-amino acids on the Fe (100) surface in gas phase.

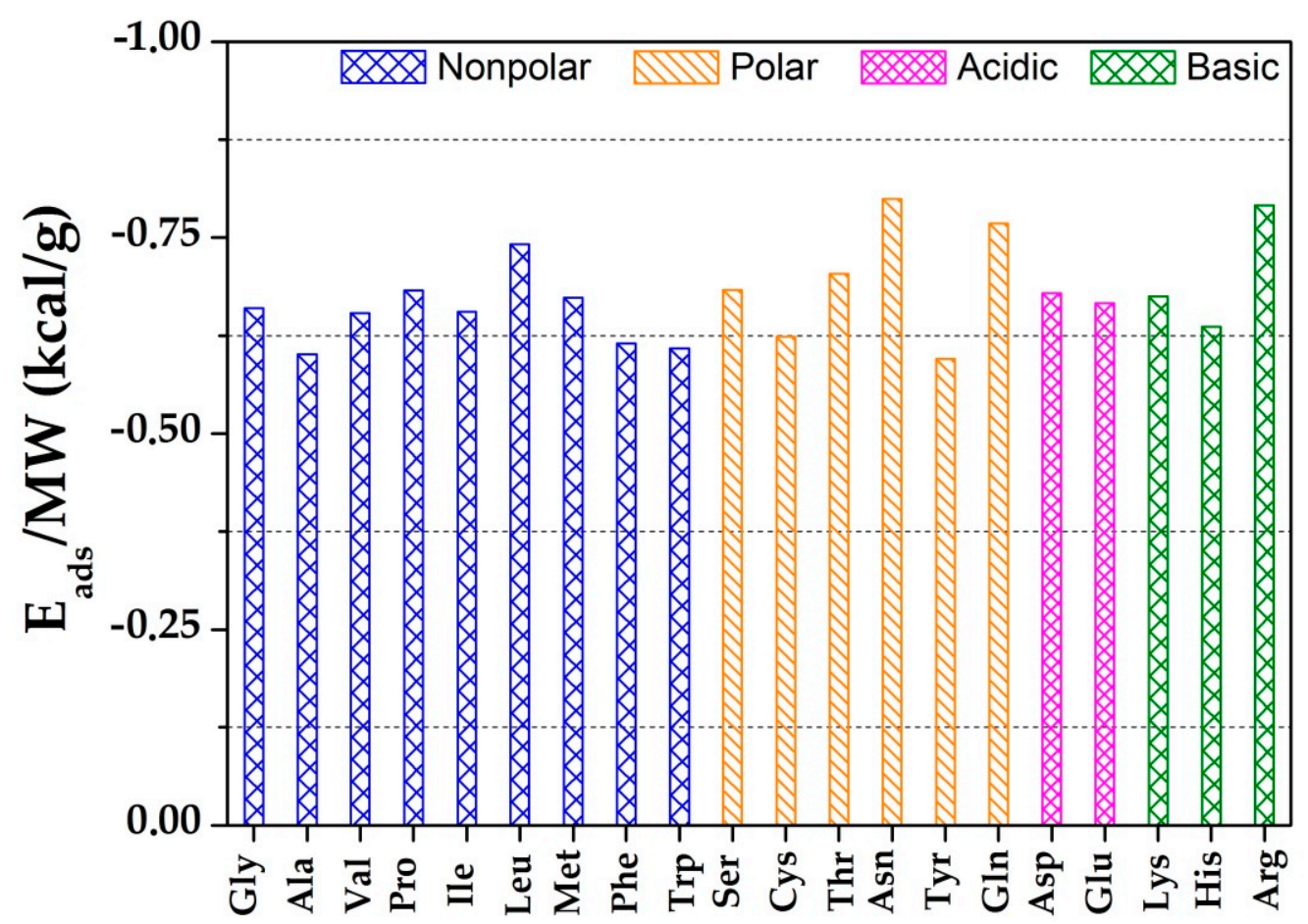

Figure 6. The specific adsorption energy $\left(\mathrm{E}_{a d s} / \mathrm{MW}\right)$ obtained from Monte Carlo simulations of L-amino acids on an Fe (100) surface in gas phase. 
The calculation results (Figure 5) agree with the experimental data [21,22,66]. In [21], it was presented that, in a hydrochloric acid solution, the inhibitory activity against the corrosion of iron Cys prevails over Ala. At the same time, in [66] the researchers explored the inhibitory activity of amino acids (Gly $<\mathrm{Ala}<\mathrm{Leu}$ ) against steel corrosion in hydrochloric acid solutions. The results demonstrated that the inhibition efficiency of amino acids ranged from $28 \%$ to $91 \%$, and these compounds are physically adsorbed on the metal surface. To inhibit the corrosion of mild steel in a hydrochloric acid solution, experimental data indicate an increase in the efficiency of amino acids in the following order: Ser $<$ Cys $<$ His $<\operatorname{Trp}$ [22]. The inhibition efficiency of L-amino acids correlates with the energy of adsorption. This happens due to the side chain length. Moreover, the inhibition efficiency changes with an increase in the number of $\mathrm{CH}_{2}$ groups in the side chain.

\section{Conclusions}

In this work, we performed a comparative systematic analysis of the inhibitory effect of L-amino acids with different side chain lengths on the Fe (100) surface in the gas phase. Monte Carlo simulations have proved that AAs can be absorbed onto the iron surface, maximizing the number of bonds formed by being horizontally positioned. The absolute values of the energy of adsorption of these inhibitors on the Fe (100) surface increase with the side chain prolongation and the number of heteroatoms in it. The calculation revealed that the maximum absolute value of the adsorption energy of L-amino acids on the iron surface in accordance with the side chain classification increases in the following sequence: Glu (acidic) < Gln (polar) < Trp (nonpolar) < Arg (basic). The findings of theoretical studies have demonstrated the promising nature of using L-amino acids from nonpolar and basic groups as effective inhibitors of iron corrosion. The calculation results agree with the experimental data.

Author Contributions: Conceptualization, A.K. and G.L.; methodology, A.K.; software, A.K.; validation, A.K. and G.L.; investigation, A.K. and G.L.; writing-original draft preparation, A.K. and G.L.; writing—review and editing, A.K. and G.L.; visualization, T.N.; supervision, A.K.; project administration, V.Y. All the authors have read and agreed to the published version of the manuscript.

Funding: The work was performed according to the state assignment of the Federal Agency for Railway Transport of the Russian Federation (protocol ROSZHELDOR of 15.04.2020 No. VCh-23).

Institutional Review Board Statement: Not applicable.

Informed Consent Statement: Not applicable.

Data Availability Statement: The data presented in this study are available on request from the corresponding author.

Acknowledgments: The research is carried out using the equipment of the shared research facilities of HPC computing resources at Lomonosov Moscow State University.

Conflicts of Interest: The authors declare no conflict of interest.

\section{References}

1. Coelho, L.B.; Taryba, M.; Alves, M.; Noirfalise, X.; Montemor, M.F.; Olivier, M.-G. The corrosion inhibition mechanisms of Ce(III) ions and triethanolamine on graphite-AA2024-T3 galvanic couples revealed by localised electrochemical techniques. Corros. Sci. 2019, 150, 207-217. [CrossRef]

2. Chaouiki, A.; Lgaz, H.; Zehra, S.; Salghi, R.; Chung, I.-M.; El Aoufir, Y.; Bhat, K.S.; Ali, I.H.; Gaonkar, S.L.; Khan, M.I.; et al. Exploring deep insights into the interaction mechanism of a quinazoline derivative with mild steel in HCl: Electrochemical, DFT, and molecular dynamic simulation studies. J. Adhes. Sci. Technol. 2019, 33, 921-944. [CrossRef]

3. Van Ooij, W.J.; Zhu, D.; Stacy, M.; Seth, A.; Mugada, T.; Gandhi, J.; Puomi, P. Corrosion protection properties of organofunctional silanes-An overview. Tsinghua Sci. Technol. 2005, 10, 639-664. [CrossRef]

4. Kosian, M.; Smulders, M.M.J.; Zuilhof, H. Structure and Long-Term Stability of Alkylphosphonic Acid Monolayers on SS316L Stainless Steel. Langmuir 2016, 32, 1047-1057. [CrossRef] [PubMed]

5. Berisha, A.; Combellas, C.; Kanoufi, F.; Pinson, J.; Podvorica, F.I. Physisorption vs. grafting of aryldiazonium salts onto iron: A corrosion study. Electrochim. Acta 2011, 56, 10762-10766. [CrossRef] 
6. Olasunkanmi, L.O.; Kabanda, M.M.; Ebenso, E.E. Quinoxaline derivatives as corrosion inhibitors for mild steel in hydrochloric acid medium: Electrochemical and quantum chemical studies. Phys. E Low Dimens. Syst. Nanostruct. 2016, 76, 109-126. [CrossRef]

7. Kuznetsov, Y.I. Triazoles as a class of multifunctional corrosion inhibitors. Review. part II. 1,2,3-benzotriazole and its derivatives. Iron and steels. Int. J. Corros. Scale Inhib. 2020, 9, 780-811. [CrossRef]

8. Dhouibi, L.; Triki, E.; Salta, M.; Rodrigues, P.; Raharinaivo, A. Studies on corrosion inhibition of steel reinforcement by phosphate and nitrite. Mater. Struct. 2003, 36, 530-540. [CrossRef]

9. Bastos, A.C.; Ferreira, M.G.; Simões, A.M. Corrosion inhibition by chromate and phosphate extracts for iron substrates studied by EIS and SVET. Corros. Sci. 2006, 48, 1500-1512. [CrossRef]

10. Hamadi, L.; Mansouri, S.; Oulmi, K.; Kareche, A. The use of amino acids as corrosion inhibitors for metals: A review. Egypt. J. Pet. 2018, 27, 1157-1165. [CrossRef]

11. El Ibrahimi, B.; Jmiai, A.; Bazzi, L.; El Issami, S. Amino acids and their derivatives as corrosion inhibitors for metals and alloys. Arab. J. Chem. 2020, 13, 740-771. [CrossRef]

12. Al-Amiery, A.A.; Kadhum, A.A.H.; Alobaidy, A.H.M.; Mohamad, A.B.; Hoon, P.S. Novel corrosion inhibitor for mild steel in HCL. Materials 2014, 7, 662-672. [CrossRef] [PubMed]

13. Odewunmi, N.A.; Mazumder, M.A.J.; Ali, S.A.; Aljeaban, N.A.; Alharbi, B.G.; Al-Saadi, A.A.; Obot, I.B. Impact of degree of hydrophilicity of pyridinium bromide derivatives on $\mathrm{HCl}$ pickling of X-60 mild steel: Experimental and theoretical evaluations. Coatings 2020, 10, 185. [CrossRef]

14. Berisha, A.; Podvorica, F.I.; Mehmeti, V.; Syla, F.; Vataj, D. Theoretical and experimental studies of the corrosion behavior of some thiazole derivatives toward mild steel in sulfuric acid media. Maced. J. Chem. Chem. Eng. 2015, 34, 287-294. [CrossRef]

15. Guo, L.; Qi, C.; Zheng, X.; Zhang, R.; Shen, X.; Kaya, S. Toward understanding the adsorption mechanism of large size organic corrosion inhibitors on an Fe(110) surface using the DFTB method. RSC Adv. 2017, 7, 29042-29050. [CrossRef]

16. Hsissou, R.; Benhiba, F.; Abbout, S.; Dagdag, O.; Benkhaya, S.; Berisha, A.; Erramli, H.; Elharfi, A. Trifunctional epoxy polymer as corrosion inhibition material for carbon steel in $1.0 \mathrm{M} \mathrm{HCl}$ : MD simulations, DFT and complexation computations. Inorg. Chem. Commun. 2020, 115, 107858. [CrossRef]

17. Hsissou, R.; Abbout, S.; Seghiri, R.; Rehioui, M.; Berisha, A.; Erramli, H.; Assouag, M.; Elharfi, A. Evaluation of corrosion inhibition performance of phosphorus polymer for carbon steel in [1 M] HCl: Computational studies (DFT, MC and MD simulations). J. Mater. Res. Technol. 2020, 9, 2691-2703. [CrossRef]

18. Khaled, K.F. Monte Carlo simulations of corrosion inhibition of mild steel in $0.5 \mathrm{M}$ sulphuric acid by some green corrosion inhibitors. J. Solid State Electrochem. 2009, 13, 1743-1756. [CrossRef]

19. Khaled, K.F.; Abdelshafi, N.S.; El-Maghraby, A.A.; Aouniti, A.; Al-Mobarak, N.; Hammouti, B. Alanine as Corrosion Inhibitor for Iron in Acid Medium: A Molecular Level Study. Int. J. Electrochem. Sci. 2012, 7, 12706-12719.

20. Zerfaoui, M.; Oudda, H.; Hammouti, B.; Kertit, S.; Benkaddour, M. Inhibition of corrosion of iron in citric acid media by aminoacids. Prog. Org. Coat. 2004, 51, 134-138. [CrossRef]

21. Amin, M.A.; Khaled, K.F.; Mohsen, Q.; Arida, H.A. A study of the inhibition of iron corrosion in $\mathrm{HCl}$ solutions by some amino acids. Corros. Sci. 2010, 52, 1684-1695. [CrossRef]

22. Fu, J.-J.; Li, S.-N.; Wang, Y.; Cao, L.-H.; Lu, L.-D. Computational and electrochemical studies of some amino acid compounds as corrosion inhibitors for mild steel in hydrochloric acid solution. J. Mater. Sci. 2010, 45, 6255-6265. [CrossRef]

23. Khaled, K.F.; Abdel-Shafi, M.S. Chemical and electrochemical investigations of L-arginine as corrosion inhibitor for steel in hydrochloric acid solutions. Int. J. Electrochem. Sci. 2013, 8, 1409-1421.

24. Singh, P.; Ebenso, E.E.; Olasunkanmi, L.O.; Obot, I.B.; Quraishi, M.A. Electrochemical, Theoretical, and Surface Morphological Studies of Corrosion Inhibition Effect of Green Naphthyridine Derivatives on Mild Steel in Hydrochloric Acid. J. Phys. Chem. C 2016, 120, 3408-3419. [CrossRef]

25. El Basiony, N.M.; Elgendy, A.; Nady, H.; Migahed, M.A.; Zaki, E.G. Adsorption characteristics and inhibition effect of two Schiff base compounds on corrosion of mild steel in $0.5 \mathrm{M} \mathrm{HCl}$ solution: Experimental, DFT studies, and Monte Carlo simulation. RSC Adv. 2015, 5, 11145-11162. [CrossRef]

26. Gece, G.; Bilgiç, S. A theoretical study on the inhibition efficiencies of some amino acids as corrosion inhibitors of nickel. Corros. Sci. 2010, 52, 3435-3443. [CrossRef]

27. El Ibrahimi, B.; Jmiai, A.; El Mouaden, K.; Oukhrib, R.; Soumoue, A.; El Issami, S.; Bazzi, L. Theoretical evaluation of some $\alpha$-amino acids for corrosion inhibition of copper in acidic medium: DFT calculations, Monte Carlo simulations and QSPR studies. J. King Saud Univ. Sci. 2020, 32, 163-171. [CrossRef]

28. National Center for Biotechnology Information (NCBI). Available online: http://pubchem.ncbi.nlm.nih.gov (accessed on 2 November 2020).

29. Radilla, J.; Negrón-Silva, G.E.; Palomar-Pardavé, M.; Romero-Romo, M.; Galván, M. DFT study of the adsorption of the corrosion inhibitor 2-mercaptoimidazole onto Fe(1 00 ) surface. Electrochim. Acta 2013, 112, 577-586. [CrossRef]

30. Liu, W.; Sun, J.; Ye, C. The influence of tensile strain on water adsorbed on Fe (100) surface: Surface chemistry aspect of stress corrosion cracking. Appl. Surf. Sci. 2019, 481, 192-199. [CrossRef]

31. Acet, M.; Zähres, H.; Wassermann, E.F.; Pepperhoff, W. High-temperature moment-volume instability and anti-Invar of $\gamma$-Fe. Phys. Rev. B 1994, 49, 6012-6017. [CrossRef] 
32. Clark, S.J.; Segall, M.D.; Pickard, C.J.; Hasnip, P.J.; Probert, M.I.J.; Refson, K.; Payne, M.C. First principles methods using CASTEP. Z. Krist. 2005, 220, 567-570. [CrossRef]

33. Sadovnichy, V.; Tikhonravov, A.; Voevodin, V.; Opanasenko, V. “Lomonosov” Supercomputing at Moscow State University. In Contemporary High Performance Computing: From Petascale toward Exascale, Chapman \& Hall/CRC Computational Science; CRC Press: Boca Raton, FL, USA, 2013; pp. 283-307.

34. Voevodin, V.; Antonov, A.; Nikitenko, D.; Shvets, P.; Sobolev, S.; Sidorov, I.; Stefanov, K.; Voevodin, V.; Zhumatiy, S. Supercomputer Lomonosov-2: Large Scale, Deep Monitoring and Fine Analytics for the User Community. Supercomput. Front. Innov. 2019, 6, 4-11. [CrossRef]

35. Perdew, J.P.; Burke, K. Generalized gradient approximation for the exchange-correlation hole of a many-electron system. Phys. Rev. B 1996, 54, 16533-16539. [CrossRef] [PubMed]

36. Perdew, J.P.; Burke, K.; Ernzerhof, M. Generalized gradient approximation made simple. Phys. Rev. Lett. 1996, 77, 3865-3868. [CrossRef]

37. Vanderbilt, D. Soft self-consistent pseudopotentials in a generalized eigenvalue formalism. Phys. Rev. B 1990, 41, 7892-7895. [CrossRef]

38. Wang, Y.; Wang, W.; Fan, K.-N.; Deng, J. Structural and electronic properties of silver surfaces: Ab initio pseudopotential density functional study. Surf. Sci. 2001, 490, 125-132. [CrossRef]

39. Kruglikov, A.; Vasilchenko, A.; Kasprzhitskii, A.; Lazorenko, G. Atomic-level understanding of interface interactions in a halloysite nanotubes-PLA nanocomposite. RSC Adv. 2019, 9, 39505-39514. [CrossRef]

40. Garrity, K.F.; Bennett, J.W.; Rabe, K.M.; Vanderbilt, D. Pseudopotentials for high-throughput DFT calculations. Comp. Mater. Sci. 2014, 81, 446-452. [CrossRef]

41. Pfrommer, B.G.; Côté, M.; Louie, S.G.; Cohen, M.L. Relaxation of Crystals with the Quasi-Newton Method. J. Comput. Phys. 1997, 131, 233-240. [CrossRef]

42. Monkhorst, H.J.; Pack, J.D. Special points for Brillouin-zone integrations. Phys. Rev. B 1976, 13, 5188-5192. [CrossRef]

43. Grimme, S. Semiempirical GGA-type density functional constructed with a long-range dispersion correction. J. Comp. Chem. 2006, 27, 1787-1799. [CrossRef] [PubMed]

44. BIOVIA, Dassault Systèmes. Materials Studio; Dassault Systèmes: San Diego, CA, USA, 2020.

45. Tang, Y.; Yang, X.; Yang, W.; Wan, R.; Chen, Y.; Yin, X. A preliminary investigation of corrosion inhibition of mild steel in $0.5 \mathrm{M}$ $\mathrm{H}_{2} \mathrm{SO}_{4}$ by 2-amino-5-(n-pyridyl)-1,3,4-thiadiazole: Polarization, EIS and molecular dynamics simulations. Corros. Sci. 2010, 52, 1801-1808. [CrossRef]

46. Feng, L.; Yang, H.; Wang, F. Experimental and theoretical studies for corrosion inhibition of carbon steel by imidazoline derivative in $5 \% \mathrm{NaCl}$ saturated $\mathrm{Ca}(\mathrm{OH})_{2}$ solution. Electrochim. Acta 2011, 58, 427-436. [CrossRef]

47. Saha, S.K.; Dutta, A.; Ghosh, P.; Sukul, D.; Banerjee, P. Adsorption and corrosion inhibition effect of schiff base molecules on the mild steel surface in 1 M HCL medium: A combined experimental and theoretical approach. Phys. Chem. Chem. Phys. 2015, 17, 5679-5690. [CrossRef] [PubMed]

48. Oguzie, E.E.; Li, Y.; Wang, S.G.; Wang, F. Understanding corrosion inhibition mechanisms-Experimental and theoretical approach. RSC Adv. 2011, 1, 866-873. [CrossRef]

49. Murti, B.T.; Putri, A.D.; Kanchi, S.; Sabela, M.I.; Bisetty, K.; Asiri, A.M. Light induced DNA-functionalized TiO 2 nanocrystalline interface: Theoretical and experimental insights towards DNA damage detection. J. Photochem. Photobiol. B 2018, 188, 159-176. [CrossRef]

50. Metropolis, N.; Rosenbluth, A.W.; Rosenbluth, M.N.; Teller, A.H.; Teller, E. Equation of state calculations by fast computing machines. J. Chem. Phys. 1953, 21, 1087-1092. [CrossRef]

51. Kirkpatrick, S.; Gelatt, C.D., Jr.; Vecchi, M.P. Optimization by simulated annealing. Science 1983, 220, 671-680. [CrossRef]

52. Černý, V. Thermodynamical approach to the traveling salesman problem: An efficient simulation algorithm. J. Optim. Theory Appl. 1985, 45, 41-51. [CrossRef]

53. Sun, H. The COMPASS force field: Parameterization and validation for phosphazenes. Comput. Theor. Polym. Sci. 1998, 8, 229-246. [CrossRef]

54. Bunte, S.W.; Sun, H. Molecular Modeling of Energetic Materials: The Parameterization and Validation of Nitrate Esters in the COMPASS Force Field. J. Phys. Chem. B 2000, 104, 2477-2489. [CrossRef]

55. McQuaid, M.J.; Sun, H.; Rigby, D. Development and validation of COMPASS force field parameters for molecules with aliphatic azide chains. J. Comput. Chem. 2004, 25, 61-71. [CrossRef] [PubMed]

56. Yang, J.; Ren, Y.; Tian, A.-M.; Sun, H. COMPASS Force Field for 14 Inorganic Molecules, He, Ne, Ar, Kr, Xe, H2, O , N $2, \mathrm{NO}_{2} \mathrm{CO}$, $\mathrm{CO}_{2}, \mathrm{NO}_{2}, \mathrm{CS}_{2}$, and $\mathrm{SO}_{2}$, in Liquid Phases. J. Phys. Chem. B 2000, 104, 4951-4957. [CrossRef]

57. Zhang, Z.; Tian, N.; Zhang, W.; Huang, X.; Ruan, L.; Wu, L. Inhibition of carbon steel corrosion in phase-change-materials solution by methionine and proline. Corros. Sci. 2016, 111, 675-689. [CrossRef]

58. El Ibrahimi, B.; Bazzi, L.; El Issami, S. The role of $\mathrm{pH}$ in corrosion inhibition of tin using the proline amino acid: Theoretical and experimental investigations. RSC Adv. 2020, 10, 29696-29704. [CrossRef]

59. Lgaz, H.; Salghi, R.; Jodeh, S.; Ramli, Y.; Larouj, M. Understanding the Adsorption of Quinoxaline Derivatives as Corrosion Inhibitors for Mild Steel in Acidic Medium: Experimental, Theoretical and Molecular Dynamic Simulation Studies. J. Steel. Struct. Constr. 2016, 2, 111. [CrossRef] 
60. Olasunkanmi, L.O.; Obot, I.B.; Kabanda, M.M.; Ebenso, E.E. Some quinoxalin-6-yl derivatives as corrosion inhibitors for mild steel in hydrochloric acid: Experimental and theoretical studies. J. Phys. Chem. C 2015, 119, 16004-16019. [CrossRef]

61. Yeh, I.-C.; Berkowitz, M.L. Ewald summation for systems with slab geometry. J. Chem. Phys. 1999, 111, 3155-3162. [CrossRef]

62. Obot, I.B.; Kaya, S.; Kaya, C.; Tüzün, B. Density Functional Theory (DFT) modeling and Monte Carlo simulation assessment of inhibition performance of some carbohydrazide Schiff bases for steel corrosion. Phys. E Low Dimens. Syst. Nanostruct. 2016, 80, 82-90. [CrossRef]

63. Eisenhauer, J.G. Degrees of freedom. Teach. Stat. 2008, 30, 75-78. [CrossRef]

64. El-Lateef, H.M.A.; Abdallah, Z.A.; Ahmed, M.S.M. Solvent-free synthesis and corrosion inhibition performance of Ethyl 2-(1,2,3,6tetrahydro-6-oxo-2-thioxopyrimidin-4-yl)ethanoate on carbon steel in pickling acids: Experimental, quantum chemical and Monte Carlo simulation studies. J. Mol. Liq. 2019, 296, 111800. [CrossRef]

65. Ouellette, R.J.; Rawn, J.D. 14-Amino Acids, Peptides, and Proteins. Princ. Org. Chem. 2015, 371-396. [CrossRef]

66. Ashassi-Sorkhabia, H.; Majidib, M.R.; Seyyedia, K. Investigation of inhibition effect of some amino acids against steel corrosion in $\mathrm{HCl}$ solution. Appl. Surf. Sci. 2004, 225, 176-185. [CrossRef] 